\title{
Epstein-Barr-Virus-Positive B-Cell Lymphoma of Recipient Origin Despite of the Elimination of Clonally EBV-Infected T Cells by Allogeneic Stem Cell Transplantation in a Patient with Chronic Active EBV Infection
}

\author{
Masayuki Nagasawa \\ Department of Pediatrics and Developmental Biology, Graduate School of Medical and Dental sciences, \\ Tokyo Medical and Dental University, 5-45, Yushima 1-chome, Bunkyo-ku, Tokyo 113-8519, Japan \\ Correspondence should be addressed to Masayuki Nagasawa, mnagasawa.ped@tmd.ac.jp
}

Received 17 December 2011; Accepted 14 February 2012

Academic Editors: C. F. Classen, C. Costa, and H. J. Jeong

Copyright ( 2012 Masayuki Nagasawa. This is an open access article distributed under the Creative Commons Attribution License, which permits unrestricted use, distribution, and reproduction in any medium, provided the original work is properly cited.

\begin{abstract}
A 20-year-old patient with chronic active EBV infection (CAEBV) received peripheral blood stem cell transplantation (PBSCT) from HLA-one-locus-mismatched mother. Although EB-virus-infected T cells were eliminated after PBSCT, she developed EBvirus-positive B-cell lymphoma of recipient origin in the brain. By reducing the immunosuppressive therapy, the initial lesion disappeared. However, another lesion in the opposite lateral brain appeared later and was resistant to further reduction of immunosuppressive therapy. EBV-DNA was persistently negative after PBSCT in the peripheral blood. This case is suggestive in management of EBV reactivation after SCT and understanding alloimmune response to EBV.
\end{abstract}

\section{Introduction}

Epstein-Barr virus (EBV) is a ubiquitously spread herpes family virus, which infects more than $90 \%$ of adults [1]. Primary EBV infection often is asymptomatic and sometimes presents as acute febrile mononucleosis. EBV usually infects $\mathrm{B}$ cells and latently infected B cells are regulated by potent T cells [2]. In an immunodeficient state, these B cells occasionally induce lymphoproliferative disease, which is sometimes life threatening [3-5].

Chronic active EBV infection (CAEBV) is another EBVrelated lymphoproliferative disease in which EBV infects $\mathrm{T}$ or NK cells $[6,7]$. Although the pathogenesis is not well understood, the prognosis is poor in the long run and allogeneic stem cell transplantation (allo-HSCT) is recommended to eradicate infected $\mathrm{T}$ or NK cells [8]. With an increased transplantation-related mortality by conventional myeloablative conditioning regimen (MAC), reduced intensity conditioning regimen (RIC) has been applied, resulting in an improved 3-year overall survival of $95.0 \pm 4.9 \%$ in RIC compared to $54.5 \pm 15.0 \%$ in MAC [9]. Recently, the author has reported that level of serum granulysin is useful for discriminating NK cell type CAEBV from T cell type [10].

The author has experienced a patient with CAEBV who developed EBV-positive B-cell lymphoma of recipient origin after allogeneic stem cell transplantation. The clinical course of this patient is suggestive to understand the significance of allo-immune response against EBV-associated lymphoproliferative diseases (EBV-LPD) in the setting of allo-HSCT.

\section{Case Report}

The patient presented with mosquito hypersensitivity at the age of five. Thereafter, she had recurrent cervical lymphadenopathy with fever, which resolved spontaneously in a couple of weeks. When she was 14 years old, systemic lymphadenopathy with fever developed. Biopsy of cervical lymph node revealed the diagnosis of Hodgkin lymphoma. She received chemotherapy of COPP/ABVD and modified EPOCH for two years. However, febrile lymphadenopathy 


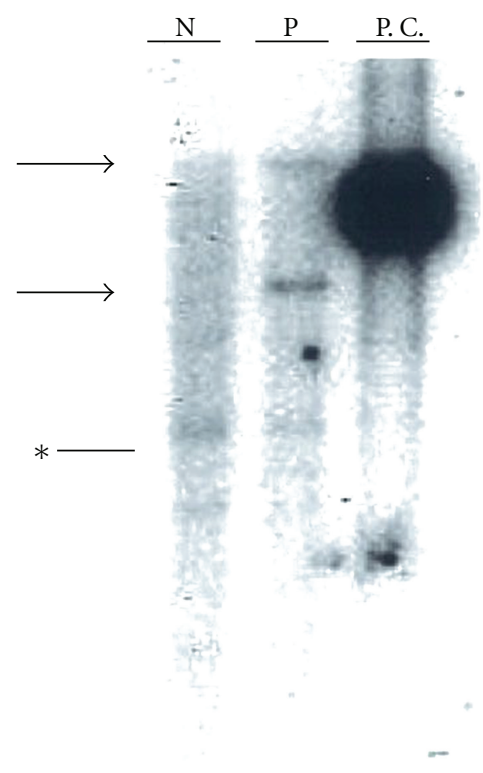

FIGURE 1: Infection status of EBV was monoclonal. DNA from the patient's peripheral blood mononuclear cells was digested by EcoRI, and southern blot hybridization was performed with EBV BamHI W probe. An arrow points at the monoclonal bands. Asterisk shows the nonspecific band. N: normal control; P: patient; P.C.: positive control (Raji cells).

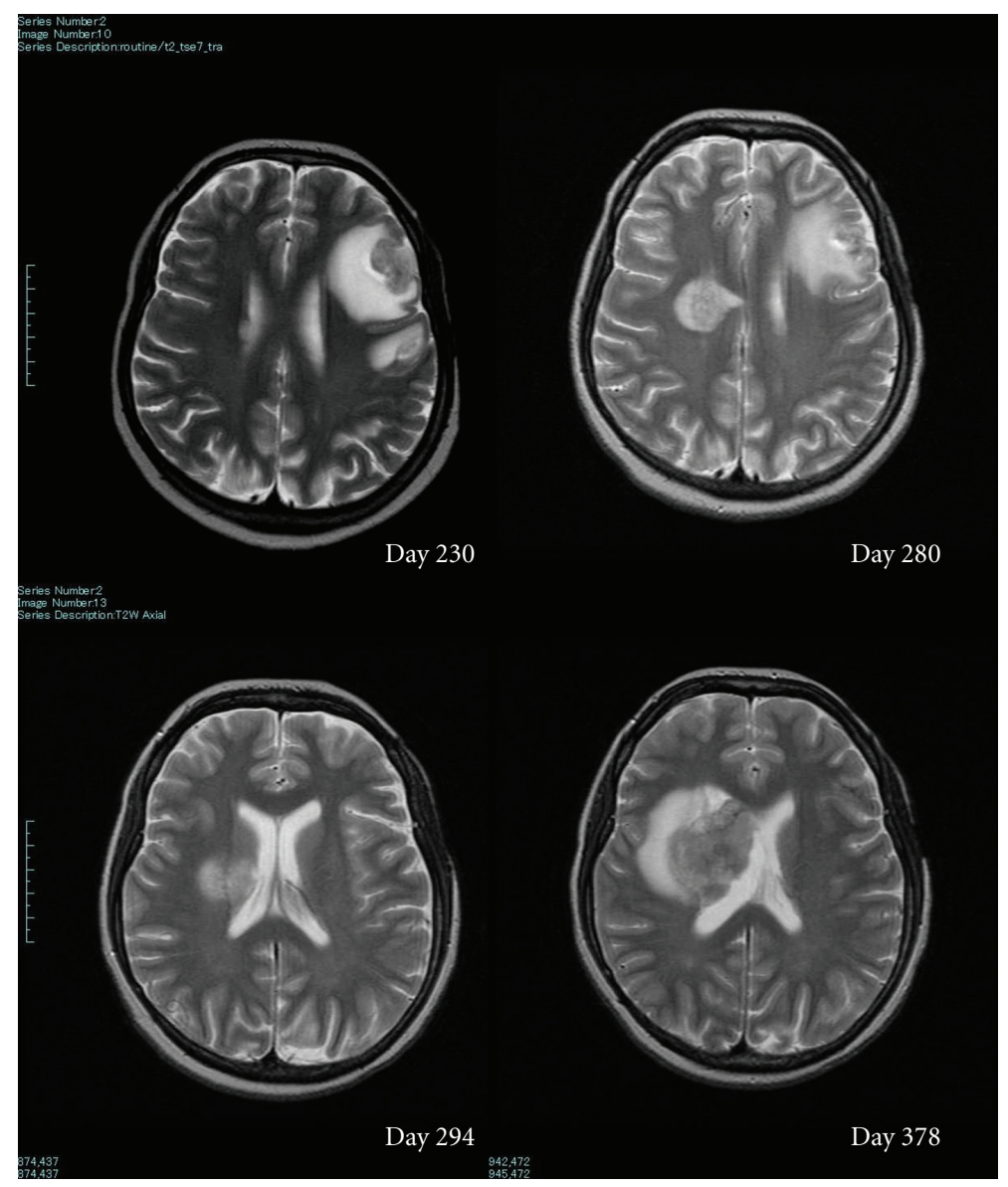

FIGURE 2: Brain MRI of the patient. Initial frontal tumor that was surrounded by T2 high edematous area disappeared completely on the 294th day, but right paraventricular tumor grew progressively. 
CD79a

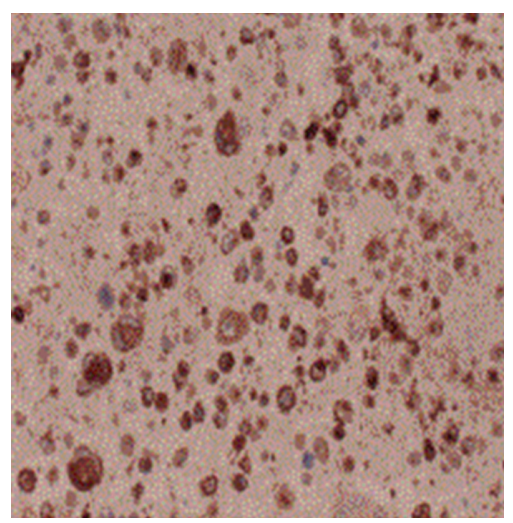

(a)

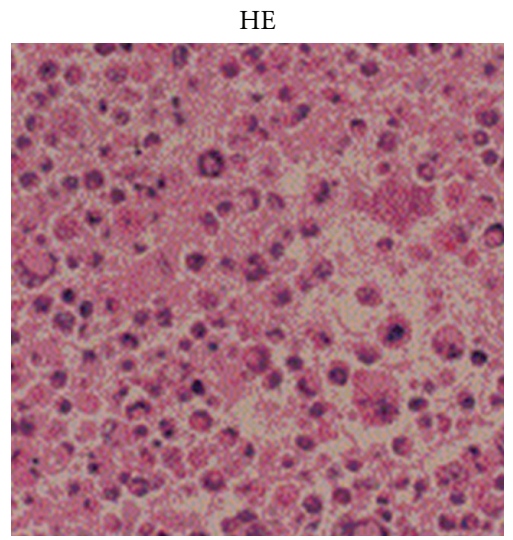

(d)
CD3

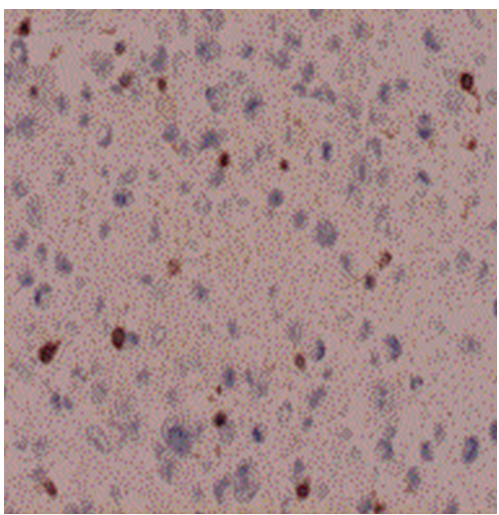

(b)

PAS

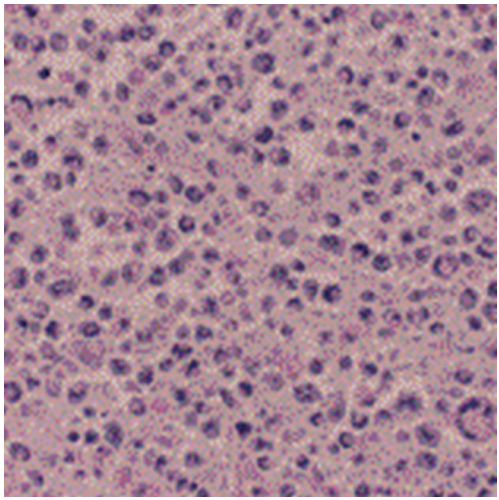

(e)
LMP-1

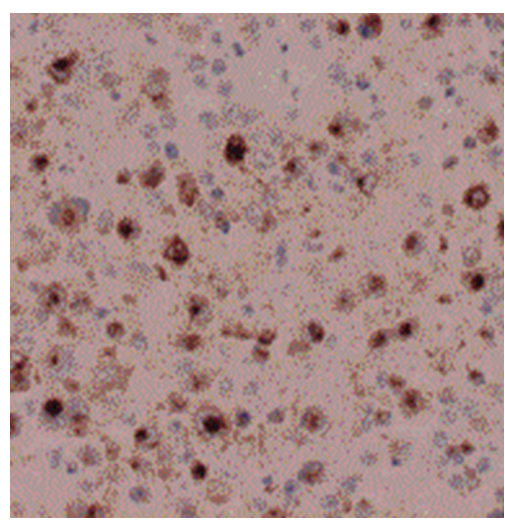

(c)

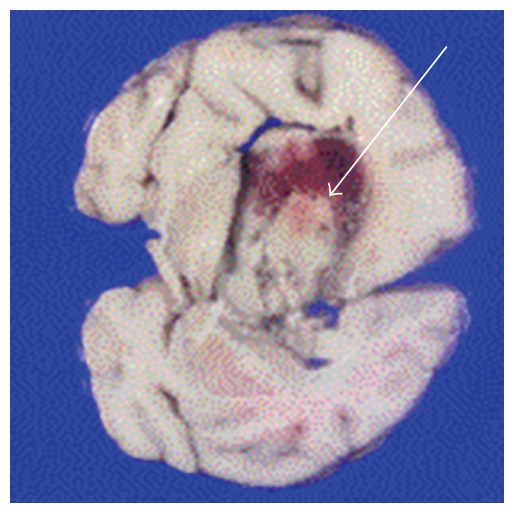

(f)

FIGURE 3: Histology of the brain tumor. Infiltrating cells in the brain tumor were CD79a+, CD3-, and LMP-1+. Arrow indicates the right paraventricular tumor.

resumed after chemotherapy. Then, she was diagnosed as chronic active EBV infection from the persistent presence of increased EBV-DNA $\left(10^{4}-10^{5}\right.$ copies $\left./ \mathrm{mL}\right)$ in the peripheral blood and high titer of anti-EB virus antibody. Analysis of lymphocyte subsets revealed that EBV infected both $\alpha \beta \mathrm{T}$ and $\gamma \delta \mathrm{T}$ cells and they were expanded clonally (Figure 1).

She was referred to our hospital at the age of 20. She received peripheral blood stem cell transplantation (PBSCT) from HLA-one-locus-mismatched mother at the age of 21 . Conditioning regimen included fludarabine $\left(25 \mathrm{mg} / \mathrm{m}^{2} \times 5\right)$, melphalan $\left(70 \mathrm{mg} / \mathrm{m}^{2} \times 2\right)$, and antithymoglobulin (Lymphoglobuline; $10 \mathrm{mg} / \mathrm{kg} \times 2$ ). GVHD prophylaxis was tacrolimus with short-term MTX. Engraftment was on the 9th day, and grade III GVHD (skin: stage 3, liver: stage 2) occurred on the 14th day, for which prednisolone and mycophenolate mofetil (MMF) were started. GVHD was intractable and grade II GVHD (skin) persisted. On the 198th day, she was discharged for follow-up of chronic GVHD on medication of tacrolimus $(0.1 \mathrm{mg} / \mathrm{kg} /$ day $)$, prednisolone $(0.5 \mathrm{mg} / \mathrm{kg} /$ day $)$, and MMF (50 mg/kg/day). EBV-DNA in the peripheral blood was turned negative on the 10th day. On the 40th day, it became transiently positive but was consistently negative after the 52nd day.
On the 227th day, she was transferred to our hospital because of convulsion. MRI revealed a mass with diameter of $20 \mathrm{~mm}$ in the left frontal lobe (Figure 2). EBV, CMV, VZV, and HHV-1, 2, 6, 7, 8 were all negative in both of the peripheral blood and spinal fluid by PCR method. Considering the EBV-associated lymphoma or toxoplasmosis, immunosuppressive drugs were reduced and antitoxoplasma drug (pyrimethamine + sulfadiazine) was started. Stage 2 skin GVHD developed, and left temporal mass was gradually regressed. However, MRI on the 280th day disclosed another mass in the right paraventricular area (Figure 1). EBV-DNA was detected in the spinal fluid on the 373rd day, although still negative in the peripheral blood. The mass was progressively enlarged in spite of stopping tacrolimus and MMF. She and her family were reluctant to further intensive therapy including radiotherapy. She died from brain stem herniation on the 417th day after PBSCT.

Autopsy revealed EBV-positive diffuse large cell lymphoma positive for CD20 and CD79a (Figure 3). Analysis of IgH and EBV terminal repeat presented monoclonal proliferation and STR (short tandem repeat) analysis showed the recipient origin (Figure 4). In the left hemisphere, ghost cells were aggregated where the first mass was detected. Ghost cells were 
Lymphoma cells

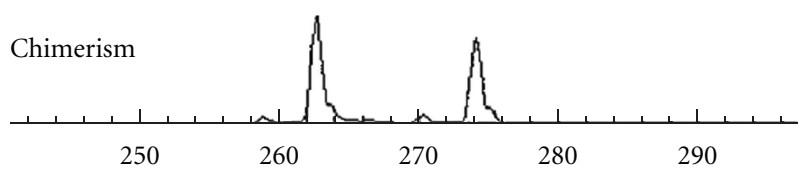

(a)

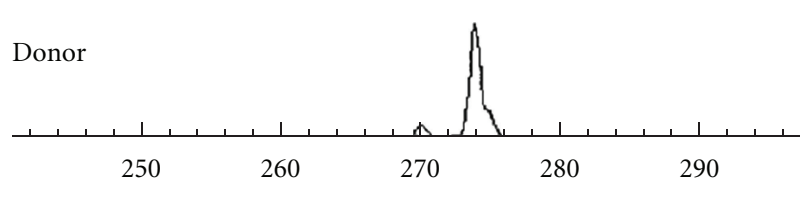

(b)

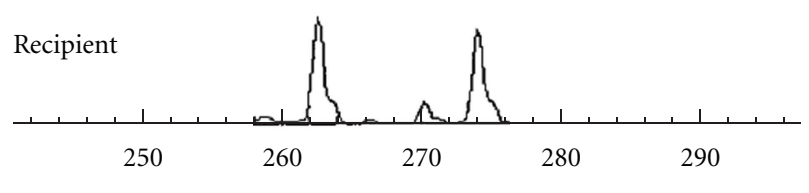

(c)

FIGURE 4: STR (short tandem repeat) analysis of the lymphoma cells.

positive for CD20 and LMP-1 (latent-membrane-protein-1) and considered to be apoptotic lymphoma cells. There was no evidence of toxoplasmosis histologically.

\section{Discussion}

It has been reported that EBV reactivation occurs in 0.6 to $26 \%$ after allo-HSCT, with this being higher in the context of T-cell depletion or prolonged immunosuppressive treatment for intractable GVHD. EBV-LPD typically occurs within the first 6 months after allo-HSCT, and mortality rates can range between 50 and $80 \%$ [11]. In most of the cases, EBVLPD arises from donor lymphocytes in allo-HSCT contrary to our case. To avoid the development of EBV-LPD, weekly screening of EBV-DNA for at least 3 months and early preemptive intervention with rituximab is recommended when EBV-DNA exceeds $10^{3}$ copies $/ 10^{5}$ cells in the peripheral blood for high-risk patients [12].

It is quite interesting that EBV-DNA was persistently negative in the peripheral blood after PBSCT in this patient, and it finally turned positive only in the spinal fluid at the later stage. This observation suggests that serial monitoring of EBV-DNA in the peripheral blood could not be sufficient enough for the detection and evaluation of EBV-LPD in the central nervous system (CNS). Isolated CNS EBV-LPD is extremely rare, and only five cases have been reported in the medical literature so far. In one case, EBV-DNA was also negative in the spinal fluid by PCR method as our case [13].

In this patient, EBV-infected $\alpha \beta \mathrm{T}$ and $\gamma \delta \mathrm{T}$ cells were eliminated after allo-HSCT, which was confirmed by the disappearance of EBV-DNA from the peripheral blood. However, EBV-positive B cell lymphoma was induced under immunosuppressive treatment for chronic GVHD.

In this case, allogeneic immune response was considered enough to eliminate EBV-infected monoclonal T cells but not
EBV-infected monoclonal B cells. One possibility is that the central nervous system was completely separated from allogeneic immune response. However, with the fact that initial brain tumor regressed after reducing immune suppressive drugs, this scenario seems not enough to explain the disease progress. Although not investigated precisely, the initial lesion in the left hemisphere could be biologically different from that in the right brain because the former regressed by reducing the immunosuppressive drugs. Recently, it has been reported that loss of alloantigen is associated with the resistance to immune surveillance system in malignant hematological disease [14]. Another possibility is that the latter lymphoma cells were more aggressively transformed to be resistant to apoptotic stimuli.

Although we could not investigate the underlining molecular mechanism in the different resistance for each lymphoproliferative disease to alloimmunity in detail, this case seems suggestive to consider the efficacy and limit of cellular immune response to EBV-related lymphoproliferative disease.

\section{Acknowledgment}

The authors wish to thank the staff of Cell Therapy Centre at Tokyo Medical and Dental University for the comprehensive virus examination for the patient's sample.

\section{References}

[1] G. Miller, "Epstein-Barr virus. Biology, pathogenesis, and medical aspects," in Virology, B. N. Fields and D. M. Knipe, Eds., chapter 68, Raven Press, New York, NY, USA, 2nd edition, 1990.

[2] C. Alfieri, M. Birkenbach, and E. Kieff, "Early events in Epstein-Barr virus infection of human B lymphocytes," Virology, vol. 181, no. 2, pp. 595-608, 1991.

[3] D. L. Birx, R. R. Redfield, and G. Tosato, "Defective regulation of Epstein-Barr virus infection in patients with acquired immunodeficiency syndrome (AIDS) or AIDS-related disorders," The New England Journal of Medicine, vol. 314, no. 14, pp. 874-879, 1986.

[4] P. S. Randhawa, R. Jaffe, A. J. Demetris et al., "Expression of Epstein-Barr virus-encoded small RNA (by the EBER-1 gene) in liver specimens from transplant recipients with posttransplantation lymphoproliferative disease," The New England Journal of Medicine, vol. 327, no. 24, pp. 1710-1714, 1992.

[5] R. S. Shapiro, K. McCLain, G. Frizzera et al., "Epstein-Barr virus associated B cell lymphoproliferative disorders following bone marrow transplantation," Blood, vol. 71, no. 5, pp. 1234$1243,1988$.

[6] H. Kanegane, K. Nomura, T. Miyawaki, and G. Tosato, "Biological aspects of Epstein-Barr virus (EBV)-infected lymphocytes in chronic active EBV infection and associated malignancies," Critical Reviews in Oncology/Hematology, vol. 44, no. 3, pp. 239-249, 2002.

[7] M. Okano, K. Kawa, H. Kimura et al., "Proposed guidelines for diagnosing chronic active Epstein-Barr virus infection," American Journal of Hematology, vol. 80, no. 1, pp. 64-69, 2005.

[8] E. Sato, S. Ohga, H. Kuroda et al., "Allogeneic hematopoietic stem cell transplantation for Epstein-Barr virus-associated 
T/natural killer-cell lymphoproliferative disease in Japan,” American Journal of Hematology, vol. 83, no. 9, pp. 721-727, 2008.

[9] K. Kawa, A. Sawada, M. Sato et al., "Excellent outcome of allogeneic hematopoietic SCT with reduced-intensity conditioning for the treatment of chronic active EBV infection," Bone Marrow Transplantation, vol. 46, no. 1, pp. 77-83, 2010.

[10] M. Nagasawa, K. Ogawa, K. Nagata, and N. Shimizu, "Serum granulysin as a possible biomarker of natural killer cell neoplasms," British Journal of Haematology, vol. 148, no. 5, pp. 812-814, 2010.

[11] C. V. Paya, J. J. Fung, M. A. Nalesnik et al., "Epstein-barr virusinduced posttransplant lymphoproliferative disorders," Transplantation, vol. 68, no. 10, pp. 1517-1525, 1999.

[12] H. E. Heslop, "How I treat EBV lymphoproliferation," Blood, vol. 114, no. 19, pp. 4002-4008, 2009.

[13] M. Hamadani, L. K. Martin, D. M. Benson, E. A. Copelan, S. M. Devine, and C. C. Hofmeister, "Central nervous system post-transplant lymphoproliferative disorder despite negative serum and spinal fluid Epstein-Barr virus DNA PCR," Bone Marrow Transplantation, vol. 39, no. 4, pp. 249-251, 2007.

[14] T. Isoda, A. M. Ford, D. Tomizawa et al., "Immunologically silent cancer clone transmission from mother to offspring," Proceedings of the National Academy of Sciences of the United States of America, vol. 106, no. 42, pp. 17882-17885, 2009. 


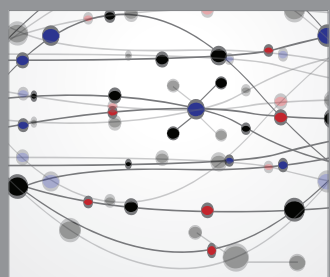

The Scientific World Journal
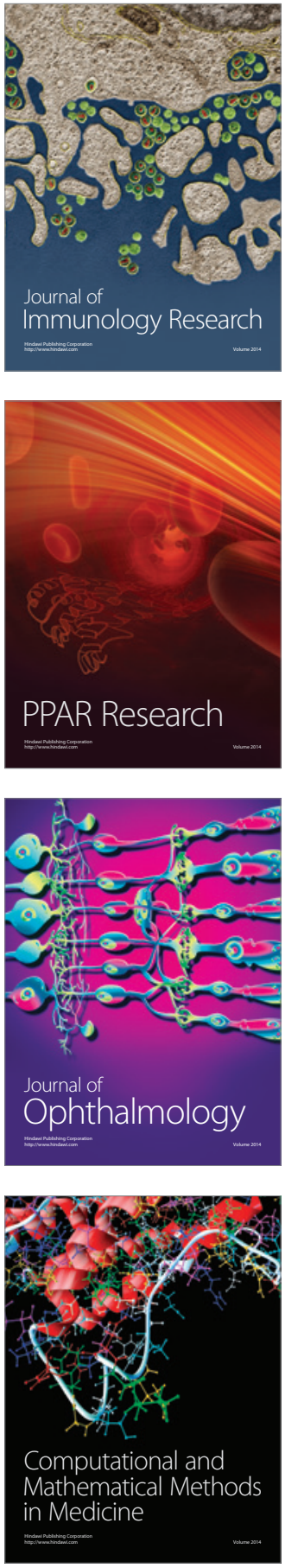

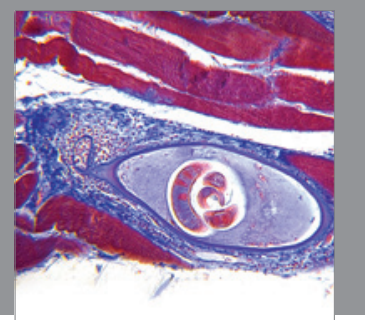

Gastroenterology

Research and Practice
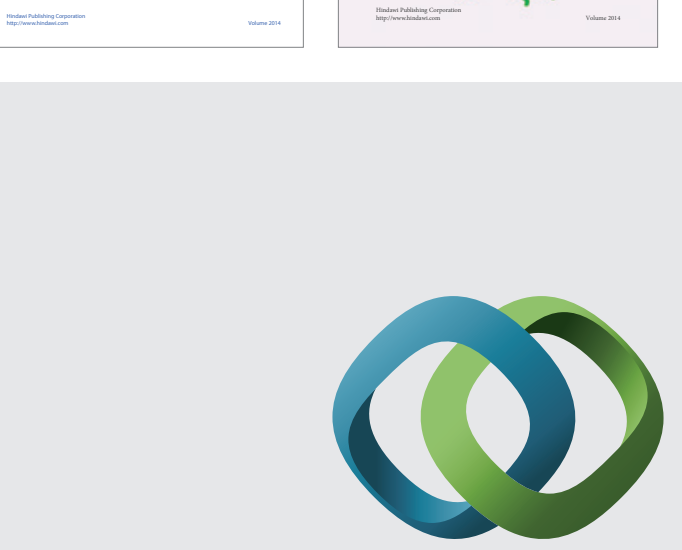

\section{Hindawi}

Submit your manuscripts at

http://www.hindawi.com
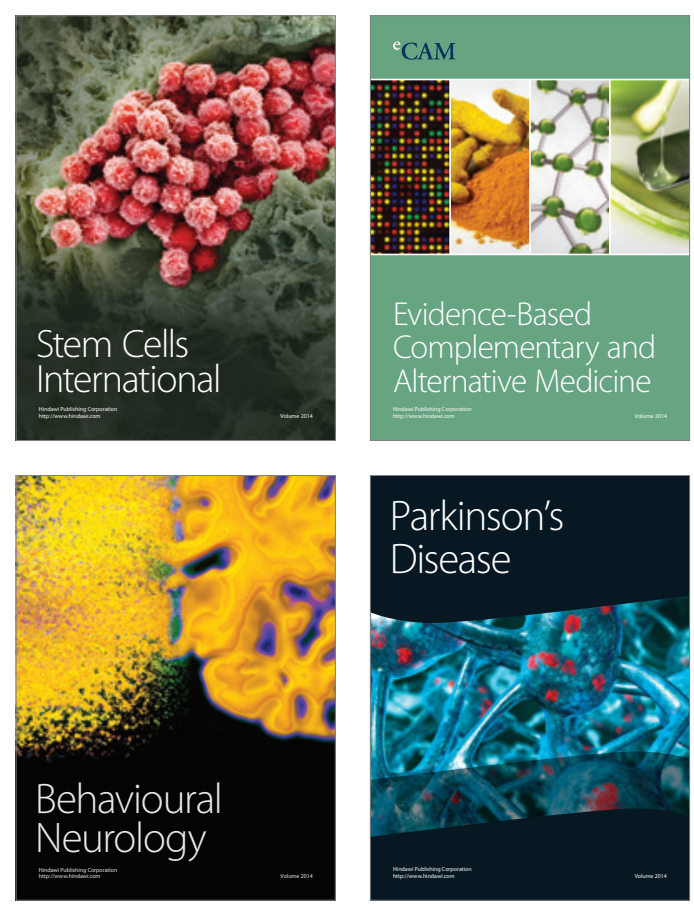

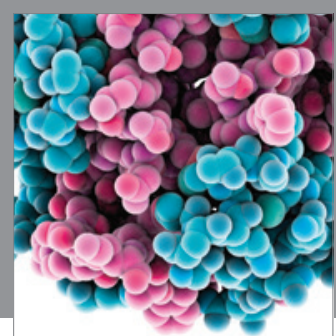

Journal of
Diabetes Research

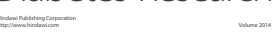

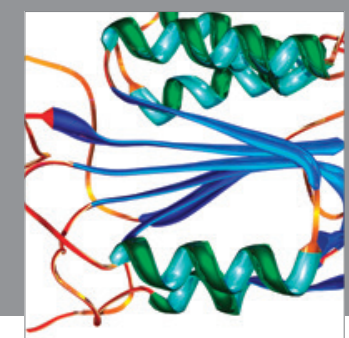

Disease Markers
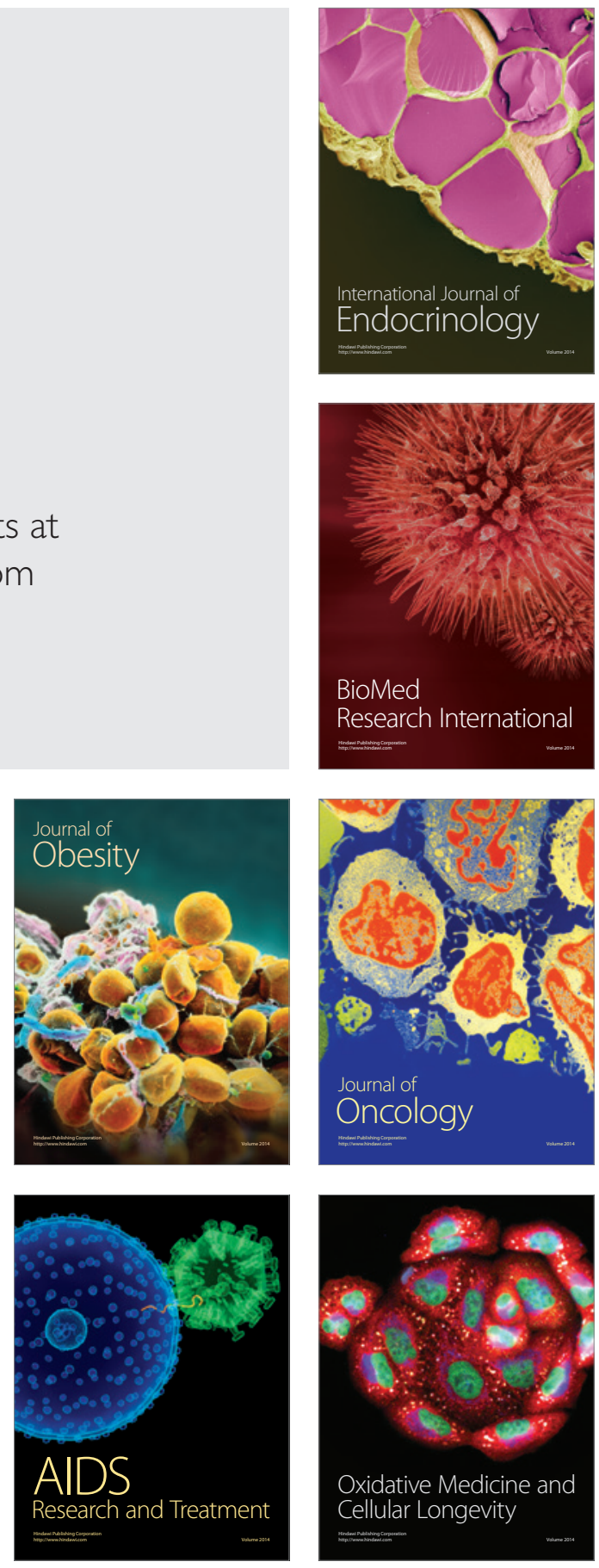